\title{
IMAGE INTERPRETATION OF COASTAL AREAS
}

\author{
M. A. Lazaridou \\ Aristotle University of Thessaloniki, Civil Engineering Faculty, Lab. of Photogrammetry-Remote Sensing. \\ P.O. Box 465, 54124 Thessaloniki, Greece \\ lazamari@ civil.auth.gr
}

Commission VIII

KEY WORDS: Image, Interpretation, Optical, Coast, SPOT

\begin{abstract}
:
Coasts were formed with the overall shape of earth's surface. They represent a landform, as determined by the science of geomorphology. Being the boundary between land and sea, they present important features - particularities such as water currents, waves, winds, estuaries, drainage network, pollution etc. Coasts are examined at various levels: continents - oceans, states - large seas, as for example Mediterranean Sea. Greece, because of its horizontal and vertical partitioning, presents great extent and variety of coasts as mainland, peninsulas and islands. Depending on geomorphology, geology, soils, hydrology, land use of the inland and the coasts themselves, these are very diverse. Photogrammetry and Remote Sensing (defined by Statute II of ISPRS) is the art, science, and technology of obtaining reliable information from non-contact imaging and other sensor systems about the Earth and its environment, and other physical objects and of processes through recording, measuring, analyzing and representation. This paper concerns critical considerations on the above. It also includes the case of Thessaloniki coasts in Greece, particularly river estuaries areas (river delta). The study of coastal areas of the wide surroundings of Thessaloniki city includes visual image interpretation digital image processing techniques on satellite data of high spatial resolution.
\end{abstract}

\section{INTRODUCTION}

Coasts represent a landform, as determined by the science of geomorphology. They form the boundary between land and sea.

Basic coastal features (geomorphologic, geologic, soil, hydrologic ones) reflect those of the respective inland.

Horizontal and vertical partitioning of the Greek area favours the development of coasts at great extent in mainland and islands.

Various multi-sided human activities (residential, touristic, cultural, etc.) and nature activities (formation of deltas, etc.) are developed in coastal areas.

Consequently, coasts and generally coastal areas are of great importance and for this reason different scientific disciplines are involved in their study.

In this paper, we search through the possibilities of visual interpretation of high resolution image data and enhanced image data on the study of coastal areas and particularly on the coastal area of the wide surroundings of the city of Thessaloniki in northern Greece.

\section{STUDY AREA}

This paper concerns the coastal area of the wide surroundings of the city of Thessaloniki, figure 1 .
The coastline extends over a length around Thermaikos Gulf, at the central part of which, the urban area of Thessaloniki has been developed (figure 2, number 1). Other settlements, suburban areas, are located at the eastern part of the gulf (figure 2, number 2). At the western coast of Thermaikos Gulf, four rivers (Gallikos, Axios, Loudias, Aliakmonas) discharge, presented in figure 2 with numbers 3,4,5,6 respectively. The deltas of the above rivers form an extended wetland protected by Ramsar Convention.

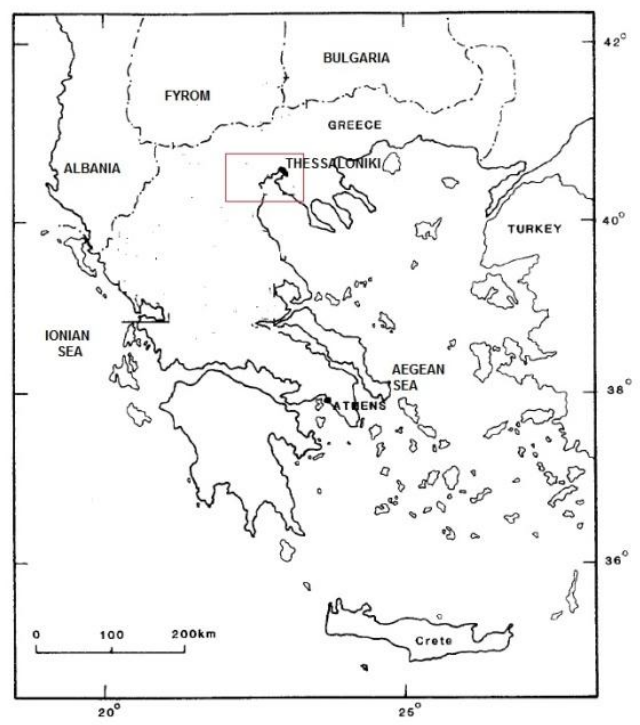

Figure 1 . The wider study area 


\section{IMAGE INTERPRETATION}

The satellite data, used in this paper, are SPOT Panchromatic image, dated 2007-10-05, preprocessing level 2A, resolution $10 \mathrm{~m}$. The study - image interpretation is done with ERDAS Imagine 2011 software and it particularly concerns Gallikos and Axios river delta areas.

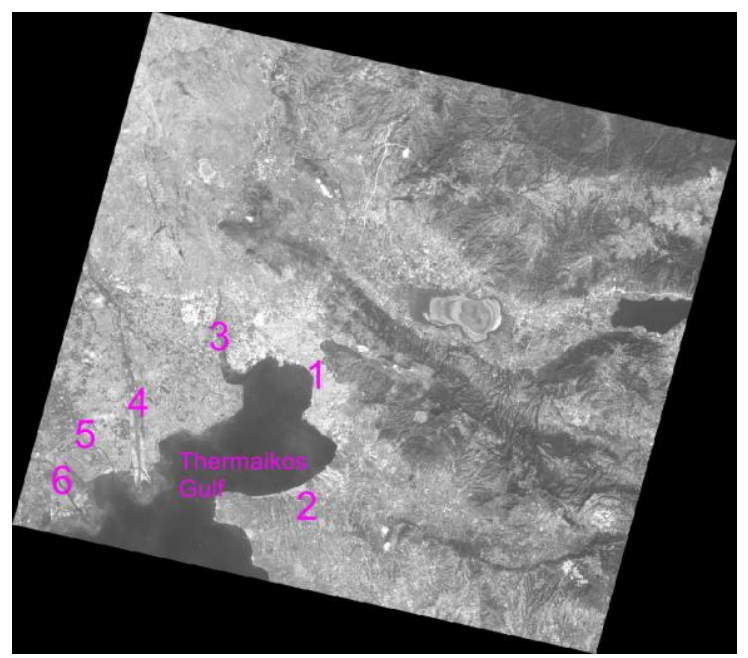

Figure 2. SPOT image of the wider study area

Two portions of the above image were selected with the software, subsetting delta area of Gallikos (figure 2, number 3) and Axios (figure 2, number 4) rivers.

Visual image interpretation of these subsetting images followed, on the base of geometric (shape, size, etc.) and radiometric (tone, texture) characteristics.

Enhancement techniques (digital image processing) were applied, next, to make the image more interpretable for the application (Erdas Field Guide ${ }^{\mathrm{TM}}, 2010$ ).

Particularly, we applied: a) point based operations (operations dealing with a single pixel) and b) local operations (the output value at a specific coordinate is dependent on the input values in the neighbourhood of that same coordinate) (ASPRS, 2004).

In this way, the following were done respectively: a) histogram equalization (non-linear contrast stretch) and brightness inversion (opposite contrast of the original image) and b) highpass filtering and edge detection with Sobel operator (zero-sum kernels convolved separately with the original image and then combined) (Erdas Field Guide $\left.{ }^{\mathrm{TM}}, 2010\right)$. Below, we refer to relevant observations and comments.

Gallikos (figure 2, number 3) is a small river discharging in Thermaikos Gulf, figure 3. The differentiations of tone at the mouth of the river, indicates that the water of the sea has come in the riverbed, or in other words the riverbed at the mouth has formed a lagoon (figure 3, L). Orthogonal pattern is identified on the left and right of the riverbed, corresponding to cultivated land. Tone and texture on both sides differentiate the overall appearance. Road network is also detected in the area.

After applying point operations (figure $3 a$, figure $3 b$ ), we observe that the boundaries of the cultivations in relation with the original image (figure 3 ) appear more clear. The boundaries of the lagoon also, as well road network are more discernible, while in the mouth of the river areas of low vegetation are detected.

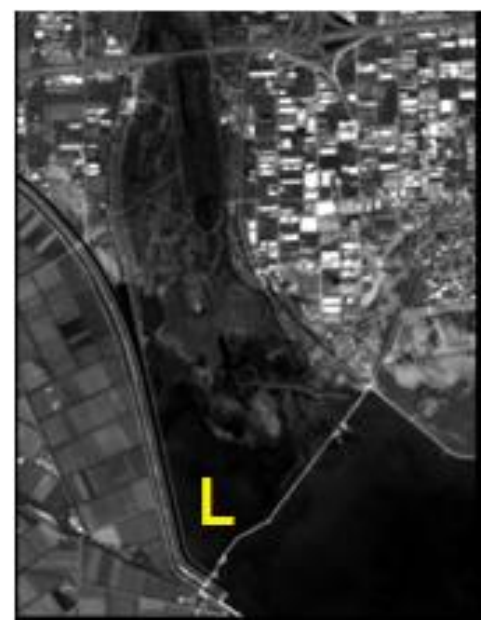

Figure 3. Gallikos river estuaries

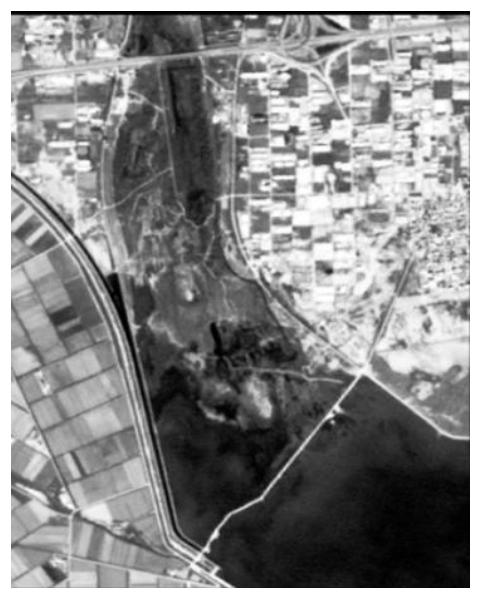

Figure 3a. Gallikos river - histogram equalization

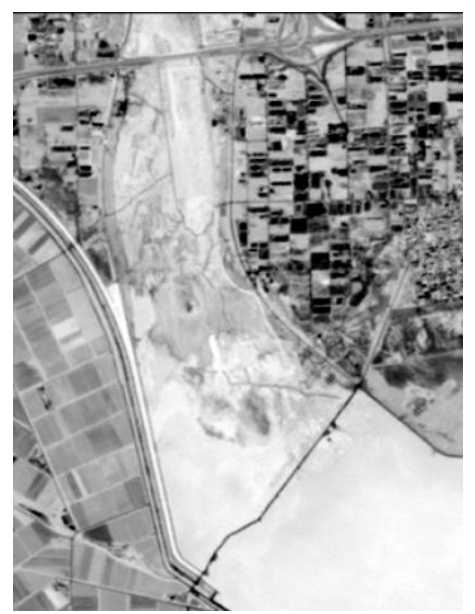

Figure 3b. Gallikos river - brightness inversion

After applying local operations (figure 3c, figure 3d) linear features are highlighted, as $3 \times 3$ high pass filtering serves as edge enhancer without eliminating other features and the application of Sobel operator shows points at which the 
intensity changes sharply, giving in this way picture of the boundaries.

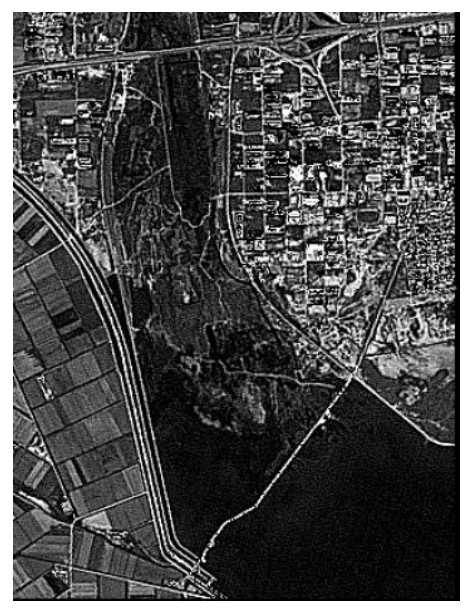

Figure 3c. Gallikos river, $3 \times 3$ high pass filtering

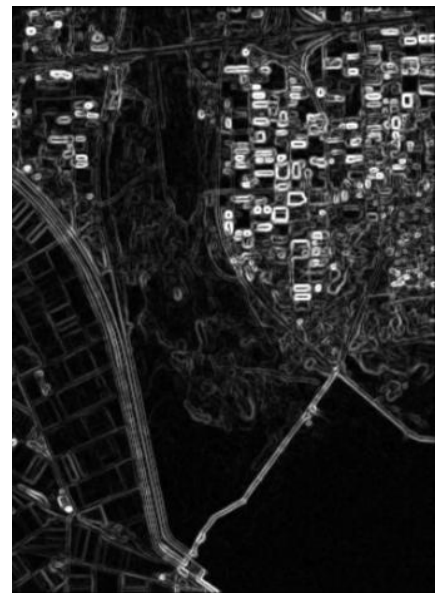

Figure 3d. Gallikos river, Sobel operator

Axios (figure 2, number 4) is an important interboundary river in northern Greece. Its estuaries in Thermaikos Gulf, form a large bird-foot delta (as defined by Zuidam et al, 1979) (figure 4).

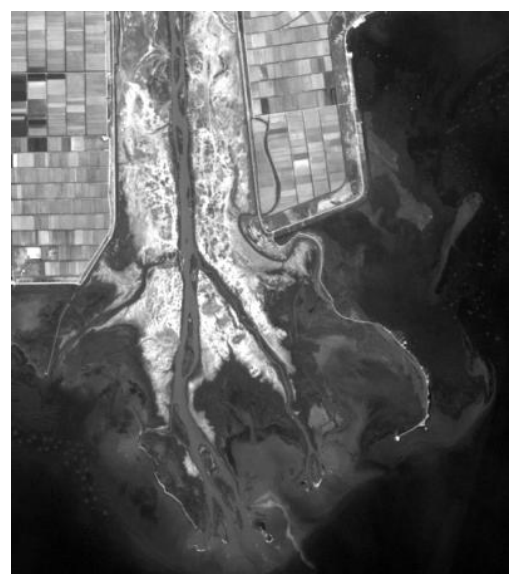

Figure 4. Axios delta
The area has been formed by a combination of fluvial processes with marine influences. Several fluvial features (as tributaries) as well low vegetation (tonal and textural differences) in the riverbed can be discerned in figure 4 . Cultivated areas on the left and right side of the riverbed and linear forms of roads are also detectable. The river transports and deposits material at the estuaries, detectable from the changes of light to dark tones in the mouth of the river (Lillesand T.M, 1987).

The application of point operations (figures $4 \mathrm{a}, 4 \mathrm{~b}$ ) substantially helps to the detection of the above. The areas of deposition in the sea have characteristic form.

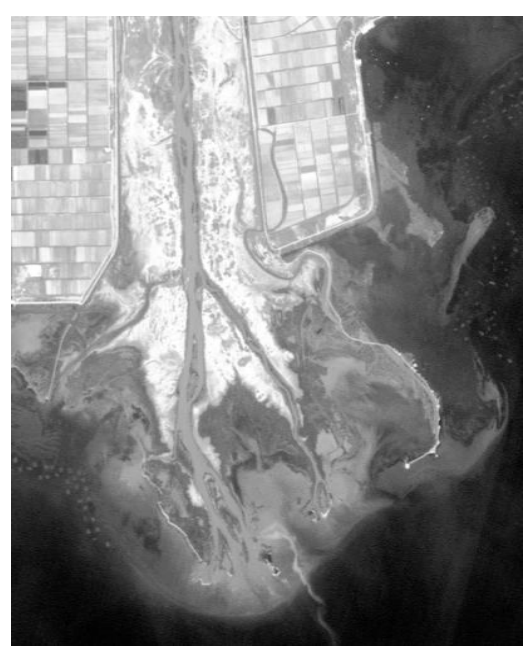

Figure 4a. Axios delta - histogram equalization

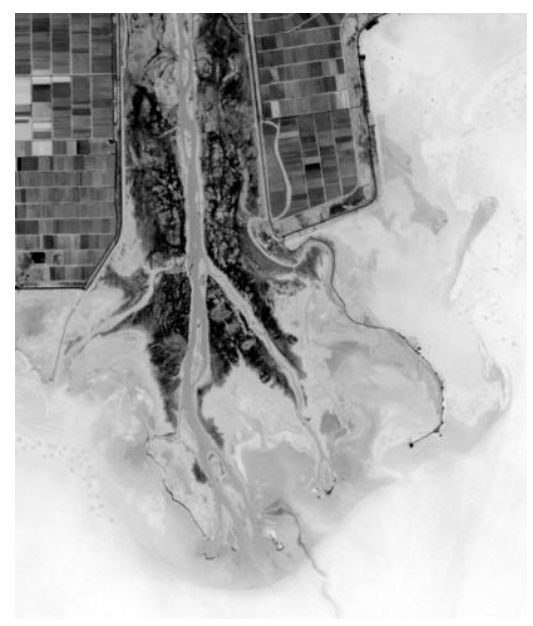

Figure 4b. Axios delta - brightness inversion

The application of local operations (figures $4 \mathrm{c}, 4 \mathrm{~d}$ ) enhances details as areas of low vegetation, cultivations, roads, riverbed boundaries and highlights the changes in image intensity detecting boundaries of similar regions. 


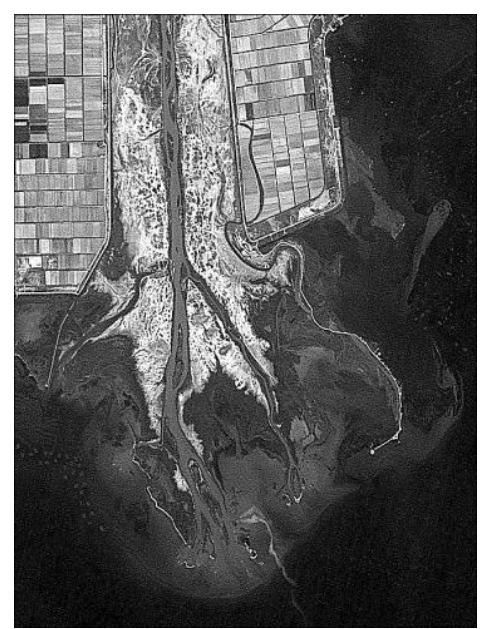

Figure 4c. Axios delta $-3 \times 3$ high pass filter

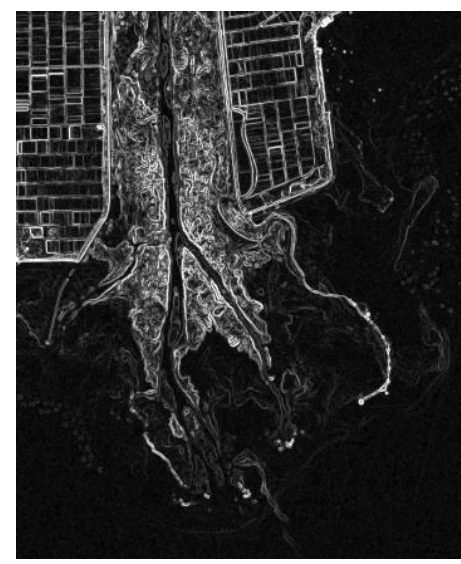

Figure 4d. Axios delta - Sobel operator

\section{DISCUSSION - CONCLUSIONS}

Geomorphology, geology, soils, land cover, land use and climate are important factors for the formation of drainage network, catchments and estuaries of a river. These factors in combination with marine influences (waves, sea currents) affect delta formation.

In this paper, we search through the possibilities of visual interpretation of primary image data and enhanced image data on the study of coastal areas of Thessaloniki and particularly on Axios and Gallikos delta area.

Visual image observation - image interpretation (photointerpetation) results in important information about the form of estuaries, Axios bird-foot delta, the formation of lagoon at Gallikos estuaries, landcover outside the riverbed, deposition areas of the transported material and for other features as roads and cultivated land. Digital image processing and particularly image enhancement make the above features more interpretable. The results of visual image interpretation of SPOT satellite image and after image enhancement are very interesting and useful for the theoretical and practical study of delta areas.

The study of coastal areas are of great importance for the Greek area (mainland - islands), concerning settlements, tourism, culture, maritime transport, delta formation etc. Photogrammetry - digital image processing and photointerpetation - image interpretation significantly contribute to this study as presented in this paper for the case of river delta areas.

\section{REFERENCES}

ASPRS, 2004. Manual of Photogrammetry, $5^{\text {th }}$ Edition. American Society for Photogrammetry and Remote Sensing, pp.416-417.

Erdas Field Guide ${ }^{\mathrm{TM}}$, 2010, Erdas Inc. U.S.A. pp.455, 474, 535.

Lillesand T.M., Keifer R.W., 1987. Remote Sensing and Image Interpretation. $2^{\text {nd }}$ Edition, John Wiley and Sons, Inc., pp. 176179.

Zuidam R.A., Zuidam-Cancelado F.I., 1979. Terrain analysis and classification using aerial photographs. ITC, The Netherlands, pp. 166. 